\title{
Effect of Educational Program about Masturbation on Blind Adolescent Students' Knowledge and Attitude
}

\author{
Hekmat Ebrahim Ebed Elkreem Mohamed, Assistant Professor \\ Pediatric Nursing, Faculty of Nursing, Assuit University \\ Sahar Sedky Faheim, Lecturer \\ Pediatric Nursing, Faculty of Nursing, Beni-Suef University \\ Rasha Mohamed Hassan Eltelt, Lecturer \\ Woman Health and Maternity Nursing, Faculty of Nursing, Kafr Elsheikh University
}

\begin{abstract}
Adolescence is a transitional stage of human physical and mental development. Masturbation is the sexual stimulation of one's own genitals for sexual arousal or other sexual pleasure, usually to the point of orgasm. Blindness is a disturbing physical condition with deep emotional and economic consequences. Objective: Identify the effect of educational program about masturbation on knowledge and attitude of blind adolescent students. Setting: The study was conducted at the outpatient students' Health Insurance Clinic and the Blind School in Benha. Subjects: A total of 120 blind adolescent students (76 males and 44 females) were recruited for this study. Tools: Tool I: structured interview sheet which included 2 parts (1): Socio-demographical data, (2): Adolescent's knowledge about masturbation, and tool II: Likert scale (Adolescent's attitude about masturbation). Results: There was a highly significant difference in pre and post-intervention program and the knowledge and attitude towards masturbation among study sample. Conclusion: Educational intervention had a significant role in increasing knowledge and changing attitude of adolescent students. Recommendations: These educational program initiatives need to be improved periodically to ensure sustainability of their positive effects on increasing knowledge and changing attitude.
\end{abstract}

Keywords: Masturbation; Blind Adolescents; Students, Educational Program; Knowledge; Attitude.

\section{Introduction}

A period in which a person becomes physically and psychologically mature and acquires a personal identity is adolescence. It is usually between $12-18$ years old, such as physical, endocrinal, emotional, and mental growth for the other developmental changes. Adolescence remains a period of "storm and stress" and is a tempestuous time charged with conflict and mood swing $^{(1)}$.

Masturbation is the self-stimulation of the sex organs, most often to the point of orgasm. Sixty to ninety percent of adolescent boys and 40 percent of girls masturbate. Although people's attitudes about masturbation differ widely, masturbation is an opportunity for private sexual exploration before deciding to engage in sexual activity with another person. It is also considered the safest form of sex in the prevention of sexually transmitted diseases, including human immunodeficiency virus $(\mathrm{HIV})^{(2,3)}$. The incidence of masturbation among males is reported more than females 7-11. In an Australian study, $58 \%$ of males and $42 \%$ of females aged 15 to 18 years masturbate. In another retrospective study, it was found that $53 \%$ of adolescent males and $25 \%$ of adolescent females begin to masturbate by the age 13 years $^{(4)}$.

Masturbation is the sexual stimulation of one's own genitals for sexual arousal or other sexual pleasure, usually to the point of $\operatorname{orgasm}^{(3)}$. The stimulation may involve hands, fingers, everyday objects, sex toys such as vibrators, or combinations of these $\mathrm{e}^{(3,4)}$. Mutual masturbation (mutual manual stimulation of the genitals between partners) can be a substitute for sexual penetration. Studies have found that masturbation is frequent in humans of both 
sexes at all ages. Various medical and psychological benefits have been attributed to a healthy attitude toward sexual activity in general and to masturbation in particular. No causal relationship is known between masturbation and any form of mental or physical disorder ${ }^{(5)}$. In relevant studies, parents have reported difficulty discussing masturbation with their adolescent children, parents usually hope that their children will view masturbation negatively ${ }^{(4)}$.

Blindness is a disturbing physical condition with deep emotional and economic consequences. Blindness is the reason of major variations in the way of life, behaviors of blind adolescent which may result in problems or complications in physical, psychological and social alterations $^{(6)}$. It has a serious effect on the adolescent students, family and community. As it is considered the most psychological and social alterations is isolation and fear from person in their family and community. Masturbation occurs in some adolescents because of a complex interaction of biological, psychological, and sociocultural factors that put forth both direct and indirect pressure on the adolescent children. There are some variables such as early maturation, substance use, having a history of sexual abuse, and having friends who view sexual behavior as acceptable are linked to the initiation of sexual intercourse $^{(6)}$.

Parents, teachers, practitioners, and health care professionals need to understand adolescent children and contextual variables that promote sexual debuts. This is determined by the complex interaction of biological, psychological, and sociocultural factors. In Egypt, adolescents obtain very inadequate Sexual Health (SH) education through the formal school system. Both national and subnational surveys have shown that young Egyptians shortage basic information on $\mathrm{SH}$ topics and often collect information from sources that may be deceptive or inaccurate. Surveys also have shown that both young people and their parents need more information regarding these topics to be taught at school ${ }^{(7)}$. They reported that there is difficulty in discussing masturbation with their adolescent children. The parents` hope that their children will view masturbation negatively ${ }^{(4)}$.

The nurse can advocate blind adolescent students for meeting their needs by designing programs to promote their healthy life style or even jointing in teaching classes focusing on the targeted areas of nutrition, physical activity, stress management, family planning, injury prevention and health protection from hazards such as smoking, substance abuse, sexual abuse and dangers of spread of sexually transmitted diseases ${ }^{(6)}$. The nurse is having educational plans for good grades, high religiosity, family support, and parental supervision are linked to the delay of sexual intercourse.

The most common problems or complications of masturbation are damaging either one's physical or mental health, some cases of Peyronie's disease in which aggressive manipulation, such as inversion during adolescence, and bending or twisting of the penis, results in a localized benign tumor, distorting the erectile appearance ${ }^{(8,9)}$. masturbation may result in tiredness or soreness which tends to make repeated masturbation self-limiting in any case and that the volume of ejaculate is temporarily reduced in men after multiple ejaculations until normal semen volume is regained in a day or so. Also, people from a socially conservative or religious background may experience feelings of guilt during or after masturbation ${ }^{(10)}$. Other complications include back pain, effects on sexual life, urine infection, hair loss, serious infection if contaminated by germs and this may affect sexual relationship after $\operatorname{marriage}^{(4,5)}$.

\section{Significance of the study}

In Egypt, masturbation behavior is usually unacceptable. Even though there is no available official statistics about masturbation in Egypt, the numbers still would not be reliable if someone attempted to collect information. This may be 
attributed to our religion, values, beliefs and culture which refuse such behaviors. Worldwide, evidence illustrated that the experience of sexual pressure is justly prevalent among young people. Approximately $25-33 \%$ of secondary and university girls in the United States stated experiencing forced touching of sexual parts and around 10\% of college girls informed experiencing forced oral, anal, and/or vaginal intercourse. It was found that $92 \%$ of men and $77 \%$ of secondary and college girl students had masturbated in the United States ${ }^{(11)}$, where vision remains one of the most vital channels through which the adolescent is knowledgeable about environment. While the blind adolescent informed their community or explore their sexuality by touching sense and it is important in organizing experiences ${ }^{(12)}$. Therefore, it is important to prevent this problem by initial molecular diagnosis, genetic counseling and appropriate treatment especially for adolescents due to the absence of screening in Egyptian culture. Nurses can facilitate the process and offer individuals the option of support groups for families and children with sexual and inflammatory disease. Health education and the media can work together to increase awareness in the masturbated adolescent students. This significant issue encouraged the researchers to conduct this study to evaluate the effect of educational program on knowledge and attitude of blind adolescents' students regarding masturbation. Consequently, this will help in the control or prevention of health problems that may occur to those used to masturbate, such as psychological disorders, and poor relation between married people.

\section{Aim of the Study}

The aim of this study was to identify the effect of educational program about masturbation on knowledge and attitude of blind adolescents' students.

\section{Research Hypotheses:}

1. The blind adolescents' students who will attend the educational program will show an improvement in their knowledge towards masturbation.

2. The blind adolescent students who will attend the educational program will show positive attitude towards prevention of masturbation.

\section{Materials and Method}

\section{Materials}

Design: A quasi-experimental research design was used to conduct this study.

Setting: This study was conducted at the Outpatient Students' Health Insurance Clinic and the Blind School in Benha .The school has 298 students and it contains 12 classes as (6 classes for primary education, 3 classes for preparatory education and 3 classes for secondary education). Another part of the school involves areas for administration, activity, art and daily living of blind adolescent students.

Subjects: A convenience subjects including all available blind adolescent students 120 (76 males and 44 females), who are learning in Blinded School at Benha institutional setting.

-Sample size: sample size was detected based on the last numbers of previous setting students who aged form 11-18 years were 171 both sex students. Sample size was calculated utilizing the following formula $^{(13)}$ :

$$
\mathrm{n}=\frac{\mathrm{N}}{1+\mathrm{N}(\mathrm{e})^{2}}
$$

Where:

$\mathrm{n}=$ sample size

$\mathrm{N}=$ student $(171)$

$\mathrm{e}=$ margin error $(0.05)$

A total of sample size was 120 blind adolescents' students.

Tools: In order to fulfill the aim of the present study, two tools were used for data collection:

\begin{tabular}{lll} 
Tool I: & Masturbation & students' \\
\hline knowledge & Structured & Interview \\
\hline questionnaire Sheet &
\end{tabular}


It was developed by the researchers after reviewing literature to assess the following parts:

Part (1): Socio-demographic data of the students, including (age, sex. birth older and residence, level of education, exercise type, cause of blindness and relation with family and friends).

Part (2): Adolescent's knowledge about masturbation such as (definition, causes, manifestations, factors, child feeling, behaviors and frequent cues often associated with masturbation, complications and reducing or preventing method) ${ }^{(4)}$.

\section{Scoring system:}

Scoring system was followed to obtain the outcomes of student knowledge.

- Knowledge contents were divided into 15 questions and each question was assigned a score and three score level; a score of (3) is considered correct \& complete, Incomplete correct answer was scored (2), while don't know or wrong answer was scored (1).

- The total score of knowledge' questionnaire responses was $100 \%$. Accordingly, more than or equal $70 \%$ was considered satisfactory, less than $70 \%$ was considered unsatisfactory.

\section{Tool II: Masturbation Likert Scale}

This scale was developed by the researchers to assess adolescent students' attitude about masturbation. It based on recent literature review and adolescent students needs to assess students' attitude and reasons about masturbation ${ }^{(14)}$.

\section{Scoring system:}

Scoring system was followed to obtain the outcomes of student' attitude:

- Masturbation likert scale: It was used twice for evaluation first as a base line assessment \& second after program implementation.

- The 30 -items questionnaire consists of 15 positive and 15 negative statements about masturbation. Likert scale scores were classed as follows: (2) score for Agree which was considered positive attitude and (1) score for Disagree which was considered negative attitude.

- The total score of attitude' questionnaire responses was $100 \%$, accordingly more than $70 \%$ was considered positive, less than $70 \%$ was considered negative.

\section{Method}

- An official permission to carry out the study was obtained from the institutional directors at the selected settings, after explaining the aim of the study.

- An ethical approval was taken from the ethics committee of faculty of Nursing of Beni Suef

- Validity of the study tools was estimated by 5 experts in Pediatric and Maternity \& Gynecological Nursing field to test content validity and its result was $95 \%$. Modifications of the tools were done according to the judgment panel on clarity of sentences, appropriateness of content and sequence of items.

- Reliability: Internal consistency of tool one was estimated by Alpha Cronbach test and its result was $\mathrm{R}=0.86$

- A pilot study was conducted on $10 \%$ (12) students to test clarity, feasibility of the two tools, and the necessary modifications were done accordingly.

\section{- Educational program:}

- The main objective of the study is identify the effect of educational program on knowledge and attitude of blind adolescents' students regarding masturbation.

- Conduction of theoretical part was preformed through lectures and group discussions. It was taken in 2 sessions (each session for 30-45 minutes) and cover the following items. The sessions 
covered the items of educational program (definition, causes, manifestations, factors, child feeling, behaviors and frequent cues often associated with masturbation, complications and reducing or preventing method.) and adolescent students' attitude about masturbation.

- The teaching methods used were discussions, brainstorming and handouts of the educational program were given to the institutional directors as a teaching media.

- It was verified for content validity by 5 experts in the field of maternity \& gynecological nursing professors and pediatric nursing professors (University of Assiut, Kafr Elsheikh and BeniSeuf). Omission, correction and clarification of some items were done. The educational program was carried out in the following four phases:

\section{- I. Assessment phase:}

It was carried out using tool one \& two to collect baseline data and to detect students' knowledge/attitude needs.

\section{- II. Planning phase:}

Educational program was planned based on assessment phase and recent review of literature (4). It included goals \& contents.

\section{- III. Implementation phase:}

- The educational program was conducted at students` residence of institution and in the last studying day of study sample.

- The educational program was conducted through four sessions; each was between 30-45 minutes according to the students' needs and condition in groups (place and time). At the beginning of the first session, the program content and its aim were explained to the students.

- The data were collected during a period of 12 months from the beginning of March 2016 up to the end of February 2017.

- Each student was interviewed individually by the researcher. The mean time needed for each sheet was about 25-35 minutes to complete a questionnaire.

- This study was showed in five separate steps: developing interview questionnaire sheet, pilot study, assessment of baseline students' knowledge and attitude (pre-test), implementation of educational program and evaluation of students' knowledge and attitude after educational program intervention.

- Each session was started by a summary about what has been conversed in the previous one and presenting the objectives of the new session using simple Arabic language, also the session was finished by a summary of its content and feedback was gained to ensure that they got the maximal benefit.

- The total number of the subjects was 120 students; they were divided into 9 groups13-14 students in each group. The program was presented to each group separately.

- The teaching methods used were discussions, brainstorming. Brill booklets were distributed as a teaching media. Handouts of the educational program were given to the institutional directors as a teaching media.

- The educational program was carried out in the following four session: 
- First session contents were (aim of the program, definition of masturbation, masturbation's cause and masturbation's

manifestations).

- Second session contents were (masturbation's complication and systematic inflammation, healthy action for masturbation and systematic inflammation and healthy personal hygiene).

- Third session contents were (common behaviors associated with masturbation, common feelings associated with masturbation, elements frequently associated with masturbation).

- Fourth session contents were (associated problems of masturbation, methods of reducing and preventing masturbation and inflammation).

\section{- IV. Program evaluation:}

The effect of the program on the study subjects was carried out through comparing the pre and post immediately assessment score of students knowledge \& attitude.

\section{Ethical considerations:}

- The aim of the study was explained to the students who participated in the research before applying the tools to gain confidence and trust.

- An oral consent was obtained from each subject participating in the program, informing them that they have the right to withdraw at any time without giving any reason.

- The study was conducted in a suitable place to keep privacy of students.

\section{Statistical Analysis}

The data were computerized and analyzed using the statistical package for social science (SPSS) version 16.0. Data were presented using:

- Descriptive statistics in the form of number, percentages means and standard deviation.

- Statistical tests included: Chi-square $(\chi 2)$ test for analysis of qualitative variables.

- The graphical presentation included pie and column chart diagrams.

- Statistical significance was considered at $\mathrm{P}$-value $<0.05$.

\section{Results}

Table (1): The demographic data of students indicated that, $54.1 \%$ of the studied students age ranged between 15-18 years with mean age $10.35 \pm 1.78$ years. More than one third of them $(37.5 \%)$ were the second child in the family. Regarding the level of education, more than half $(58.3 \%)$ of the students had basic education. As regards residence, $66.7 \%$ were from rural community and nearly $58.3 \%$ had genetic cause of blindness and $50 \%$ of the students had good relation with family and friends.

Table (2) points out that there was an improvement in students' knowledge postprogram in the mean score. There were highly statistically significant differences $(\mathrm{P}<0.001)$ between pre and immediately after program implementation.

Figure (1) showed that $70 \%$ of the students were residence at institute, while $30 \%$ of them were not residence at institute.

Figure (2) showed that $88 \%$ of the students had unsatisfactory in their total scores of knowledge and $12 \%$ of them had satisfactory level before program intervention. While the same figure displayed that more than three quarters of the studied students (93\%) had satisfactory level in their scores of knowledge and 7\% 
had an unsatisfactory level after program intervention.

Figure (3) illustrated that the female and male students had half of their knowledge from more than one source and the minority had their knowledge from health team.

Table (3) pointed out that there were highly statistically significant differences $\left(\mathrm{P}<0.001^{* *}\right)$ between knowledge score and their socio demographic characteristics between pre and post-intervention program in educational level, residence and relation with family and friends.

Figure (4) showed that $91.2 \%$ had negative attitude and $8.8 \%$ had positive attitude before program intervention. While the same figure displayed that, more than three quarters of the studied students $(84.3 \%)$ had positive attitude and $15.7 \%$ had negative attitude after program intervention.

Table (4) pointed out that there were highly statistically significant differences $\left(\mathrm{P}<0.001^{* *}\right)$ between attitude score and its socio demographic characteristics about pre and post-intervention program in age, order, educational level, residence and relation with family and friends.

Table (5) showed a statistically significant positive correlation between students total knowledge scores after program implementation and their attitude immediately after program implementation.

Table (6) showed that nearly the majority of the studied students had positive opinion about masturbation educational program according to knowledge, time, language, discussion methods and place of the program.

\section{Discussion}

Masturbation can negatively impact the relationships and everyday life of the person. There are significant changes occurs in chemistry of the body when one masturbates excessively, which may be lead to some complications such as feeling of guilty about masturbating because of cultural, spiritual, or religious beliefs.
Masturbation complications include also lower back pain, fatigue, thinning hair or hair loss, a soft or weak erection, premature ejaculation, fuzzy vision, groin- or testicular pain and pains or cramps in the pelvic area or tail bone ${ }^{(15)}$.

The purpose of this study was to design, implement and evaluate the effect of educational program on knowledge and attitude of blinded adolescents' students regarding masturbation. Findings of this study will be discussed to support the research hypotheses;

H1: The blind adolescents' students who will attend the educational program will show an improvement in their knowledge towards masturbation.

$\mathrm{H} 2$ : The blind adolescent students who will attend the educational program will show positive attitude towards prevention of masturbation.

The findings of the current study supported the first researchers hypothesis which stated that blinded adolescent's students who attended the educational program had improvement in knowledge and attitude towards prevention of masturbation.

The findings of this study found that blind adolescents had poor knowledge related to masturbation and there was a highly statistically significant difference $(\mathrm{P}<0.001)$ between pre and immediately after program implementation. These findings agreed with those of Wang et al. (2017) who investigated the relationship between masturbatory knowledge and masturbatory attitudes among Taiwan adolescents, and reported that adolescents in Taiwan had insufficient knowledge regarding masturbation ${ }^{(16)}$. Moreover, Wilson \& Medora (2015), who did Questionnaires to 641 undergraduates at a large Southeastern University to assess their knowledge related to masturbation and stated that undergraduates' students had poor knowledge related to masturbation ${ }^{(17)}$. Also, Garde \& Lunde (2010) showed that during childhood there was very poor 
knowledge related to masturbation ${ }^{(18)}$. The researcher stated that in all studies done in Egypt because of the parents have reported difficulty in discussing masturbation with their adolescent children, the parents` hope that their children will view masturbation negatively and adolescents obtain very inadequate SH (Sexual Health) education through the formal school system ${ }^{(4)}$.

No researches were against the result of current study, (Richardsom \& Mark, 2012). From the researchers' point of view, this similarity might be due to the habit of masturbation is considered a bad habit in both developed and developing countries cultures, because most of researchers done in developed countries and this study done at developing countries. Findings of the current study found that, the study sample had half of, collectivist countries, their knowledge from more than one source $50 \%$ of them acquired their knowledge from friends, $10 \%$ from family and $9 \%$ from teacher, while the minority had their knowledge from health team. The researchers found in Egypt and Arab communities that, masturbation behaviors is uncommon and unacceptable behavior in their community and the adolescent students are considered vision the main channels which the adolescent is informed about environment, while the blind adolescent informed their community or explore their sexuality by touching sense and it is important in organizing experiences and try to gain information from any source ${ }^{(12)}$.

This finding agreed with those of Garde \& Lunde (2010) found that female students had their knowledge about masturbation from reading, friends, and school, and little knowledge from family (more than half of the study sample) followed by school, reading, parents, siblings and boyfriends ${ }^{(18)}$. While the finding of this study disagreed with study done by Hansen \& Lloyd (2015) showed in their study that, the main source of the information about masturbation acquired from friends. Also who stated that they had received too limited knowledge about masturbation or received this knowledge too late after they used to of masturbate ${ }^{(19)}$. This discrimination might be due to cultural differences among current study sample and other studies.

The current study showed that $91.2 \%$ had unsatisfactory in their total scores of attitude followed by $8.8 \%$ had satisfactory level before program intervention. While the same figure displayed that, more than three quarters of the studied students $(84.3 \%)$ had satisfactory level in their scores of knowledge followed by less than quarter had an unsatisfactory level after program intervention. This finding agreed with study done by Ray \& Afflerbach (2014) who found that participants who received positive masturbation education (at home or at school) had more positive attitudes toward masturbation than participants who received negative or no masturbation education ${ }^{(20)}$. While Hansen \& Lloyd (2015) found a significant positive relationship $(\mathrm{p}<.001)$ between attitude towards masturbation and appropriate knowledge acquired ${ }^{(19)}$.

Findings agreed with a study done by Wang et al. (2017) who investigated the relationship between masturbatory knowledge and masturbatory attitudes among Taiwan adolescents and founded that, masturbatory attitudes were positively with masturbatory knowledge and good knowledge acquired from school and parent about masturbation provide positive behavior and attitudes toward masturbation. No researches against the result of current study. The researcher stated that the study sample is mature enough because of more than half of them aged 15-18 years old and more than one third in secondary level of education and need for knowledge and information about masturbation ${ }^{(16)}$.

The current study showed that there is an improvement in students' knowledge post-program mean scores and there were highly statistically significant differences $(\mathrm{P}<0.001)$ between pre and immediately after program implementation. This finding 
agreed with (How to prevent masturbation, 2017) \& (Ways to Stop Masturbation, 2017) there are many ways to reduce masturbation habit such as removing everything that can stimulate masturbation avoiding loneliness, engaging in sport and activity, consuming fruits and vegetables that increase energy, finding someone to counsel about masturbation, and having a strong goal or motivation to stop masturbating ${ }^{(21,22)}$. The researcher opinion is the adolescent must direct toward God because of a large number of professional doctors state that masturbation is an abnormal act that's harmful for one's body that in Egypt and most Muslim countries. Masturbation is also reflected as a sin in Islam $^{(23)}$.

\section{Conclusion}

Educational intervention had a significant role in increasing knowledge and improving attitude regarding universal precautions towards masturbation among adolescent students.

\section{Recommendations}

- More efforts are needed in developing and applying similar educational endeavors for blind children about masturbation. These educational program initiatives need to be improved periodically to ensure sustainability of their positive effects on knowledge and attitude for prevention of masturbation.

- Nursing educational program should offer in Braille booklets were used as teaching media for blind students. 
Table (1): Distribution of demographic characteristics of the studied students. No=120

\begin{tabular}{|c|c|c|}
\hline Items & No & $\%$ \\
\hline \multicolumn{3}{|l|}{ Age in years } \\
\hline $11-<$ & 20 & 16,7 \\
\hline $13-<$ & 35 & 29,2 \\
\hline $15-18$ & 65 & 54,1 \\
\hline Mean \pm SD & \multicolumn{2}{|c|}{$16,35 \pm 1,78$} \\
\hline \multicolumn{3}{|l|}{ Birth order } \\
\hline First & 25 & 20,8 \\
\hline Second & 45 & 37,5 \\
\hline Third & 40 & 33,3 \\
\hline Fourth & 10 & 8,4 \\
\hline \multicolumn{3}{|l|}{ Educational level } \\
\hline Basic & 70 & 58,3 \\
\hline Secondary & 50 & 41,7 \\
\hline \multicolumn{3}{|l|}{ Residence } \\
\hline Urban & 40 & 33,3 \\
\hline Rural & 80 & 66,7 \\
\hline \multicolumn{3}{|l|}{ Cause of blindness } \\
\hline Genetic & 70 & 58,3 \\
\hline Accidental & 50 & 41,7 \\
\hline \multicolumn{3}{|c|}{ Relation with family and friends. } \\
\hline Good & 60 & 50.0 \\
\hline Fair & 40 & 33,3 \\
\hline Poor & 20 & 16,7 \\
\hline
\end{tabular}


Table (2): Percentage distribution of students' knowledge regarding masturbation pre and post implementation of the educational program $n=12$

\begin{tabular}{|c|c|c|c|c|c|c|}
\hline \multirow{3}{*}{ Items } & \multicolumn{2}{|c|}{ Pre-intervention } & \multicolumn{2}{|c|}{ Post-intervention } & \multirow{3}{*}{$\begin{array}{l}\text { Chi } \\
\text { square } \\
\text { Test(1) }\end{array}$} & \multirow{3}{*}{$P$ value } \\
\hline & $\begin{array}{c}\text { Satisfact } \\
\text { ory }\end{array}$ & $\begin{array}{c}\text { Unsatisf } \\
\text { actory }\end{array}$ & $\begin{array}{c}\text { Satisfact } \\
\text { ory }\end{array}$ & $\begin{array}{c}\text { Unsatisf } \\
\text { actory }\end{array}$ & & \\
\hline & $\%$ & $\%$ & $\%$ & $\%$ & & \\
\hline Definition of masturbation & 0.0 & 100.0 & 92.5 & 7.5 & 114.74 & $<0.001 * *$ \\
\hline Masturbation's cause & 0.0 & 100.0 & 95,0 & 5,0 & 16.82 & $<0.001 * *$ \\
\hline Masturbation's manifestations & 23,0 & 77,0 & 93,0 & 7,0 & 6,75 & $<0.001 * *$ \\
\hline $\begin{array}{l}\text { Masturbation's complication and } \\
\text { systematic inflammation }\end{array}$ & 0.0 & 100.0 & 90.0 & 10.0 & 120.00 & $<0.001 * *$ \\
\hline $\begin{array}{l}\text { Healthy action to masturbation } \\
\text { and systematic inflammation }\end{array}$ & 0.0 & 100.0 & 86.3 & 13.7 & 114.76 & $<0.001 * *$ \\
\hline Healthy personal hygiene & 8.25 & 91.75 & 87.5 & 12.5 & 16.82 & $<0.001 * *$ \\
\hline $\begin{array}{l}\text { Common behaviors associated } \\
\text { with masturbation }\end{array}$ & 7.5 & 92.5 & 86.3 & 13.7 & 114.76 & $<0.001 * *$ \\
\hline $\begin{array}{l}\text { Common feelings associated with } \\
\text { masturbation }\end{array}$ & 0.0 & 100.0 & 94.0 & 6.0 & 6,75 & $<0.001 * *$ \\
\hline $\begin{array}{l}\text { Elements frequently associated } \\
\text { with masturbation }\end{array}$ & 12.0 & 88.0 & 95,0 & 5,0 & 16.82 & $<0.001 * *$ \\
\hline $\begin{array}{l}\text { Methods of reducing and } \\
\text { preventing masturbation and } \\
\text { inflammation }\end{array}$ & 0.0 & 100.0 & 82.5 & 17.5 & 114.74 & $<0.001 * *$ \\
\hline
\end{tabular}

$\mathrm{P}<0.001 * *$ highly statistically significant

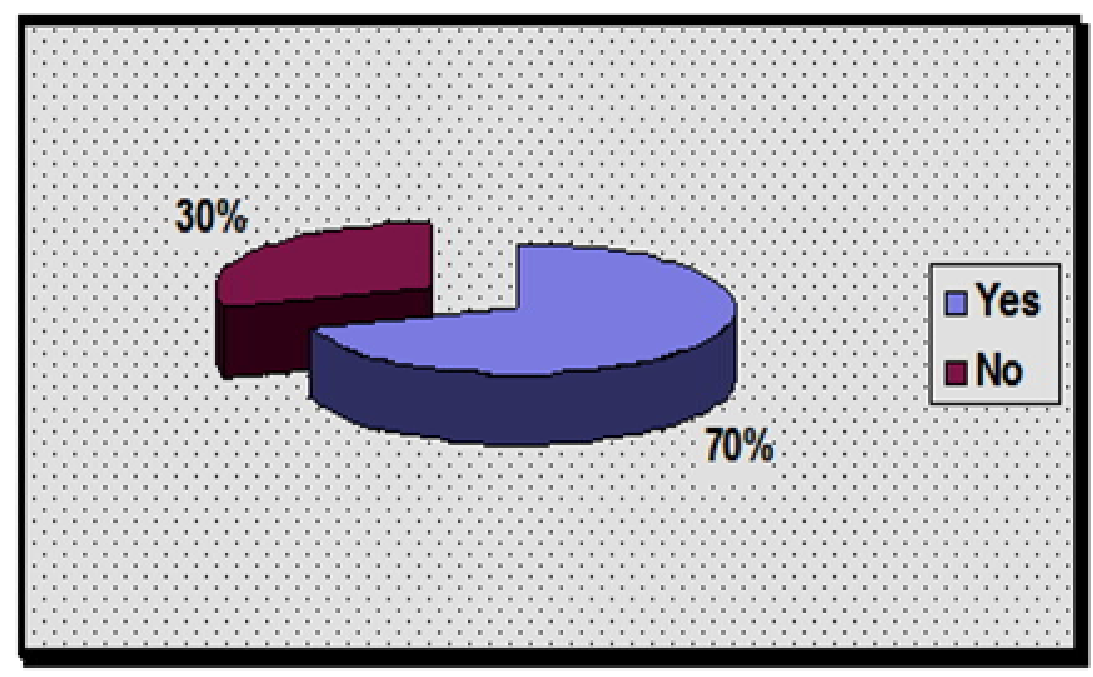

Figure (1): Frequency distribution of study sample regarding residence at institute of students. No=120 


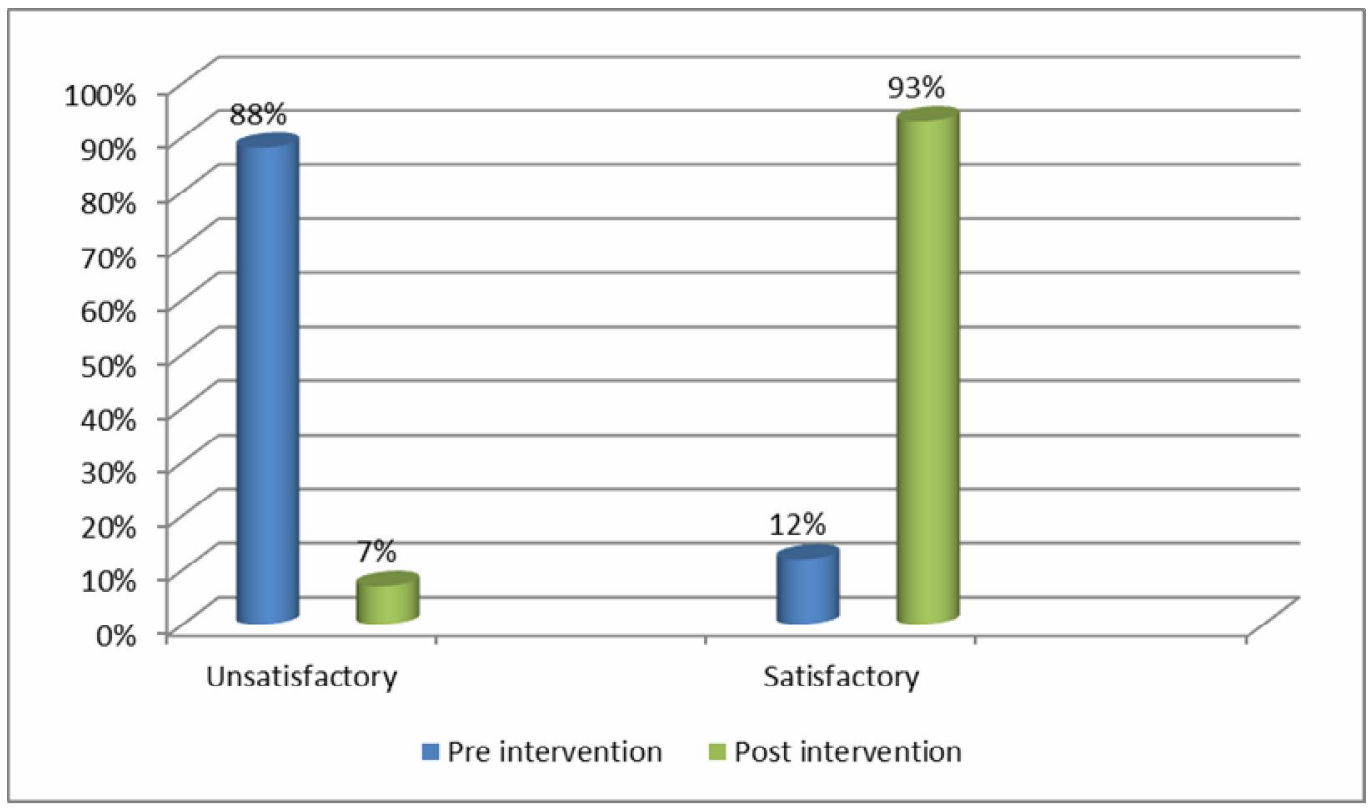

Figure (2): Percentage distribution of total knowledge score of the studied students about masturbation regarding pre and post program intervention. $\mathrm{No}=120$

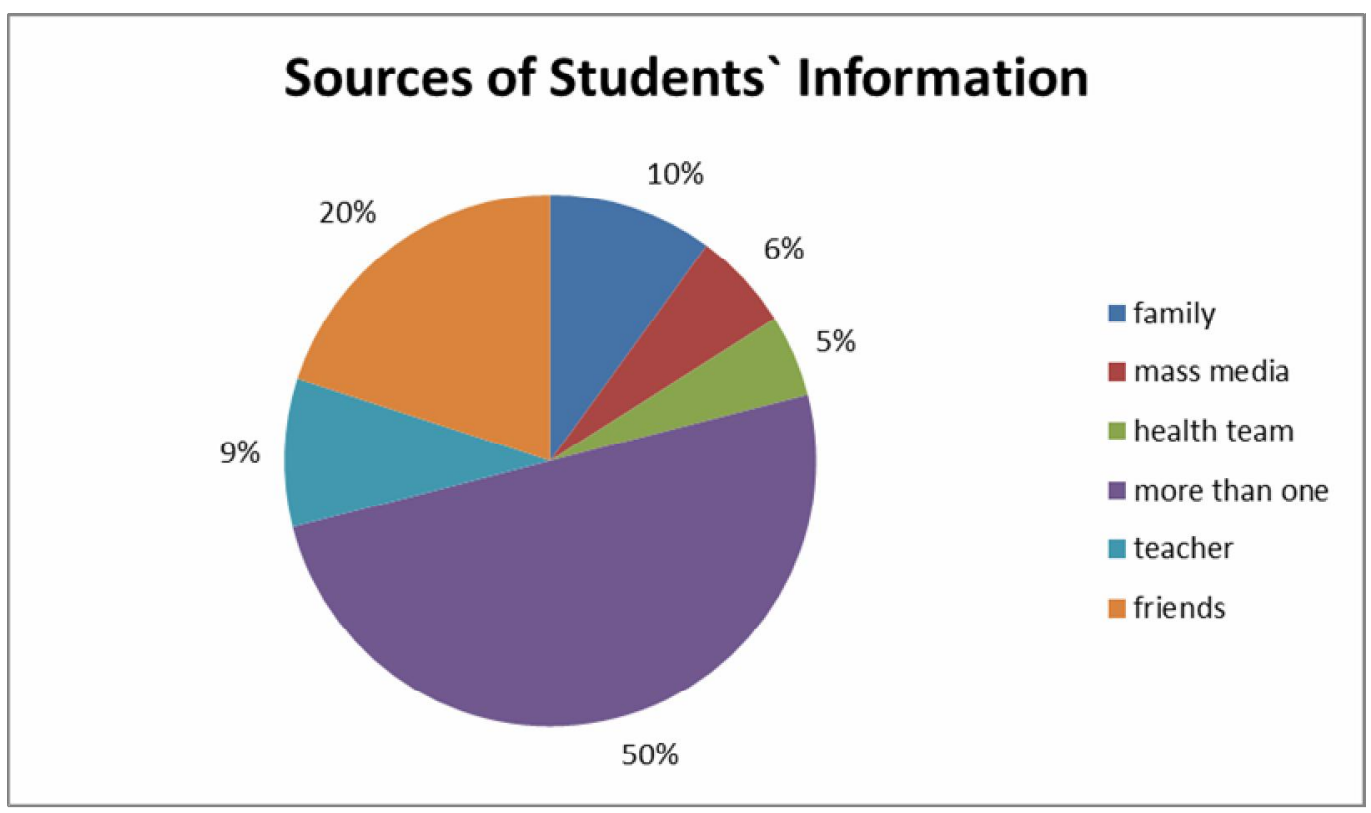

Figure (3): Distribution of the studied students regarding the source of information. No=120 
Table (3): Relation between Knowledge score and their demographic characteristics about masturbation regarding pre and post program intervention. No=120

\begin{tabular}{|c|c|c|c|c|c|c|c|c|c|c|}
\hline \multirow{4}{*}{ Items } & \multicolumn{8}{|c|}{ Total knowledge } & \multirow{4}{*}{$\begin{array}{l}\text { Chi } \\
\text { square } \\
\text { Test(1) }\end{array}$} & \multirow{4}{*}{$P$ value } \\
\hline & \multicolumn{4}{|c|}{ Pre-intervention } & \multicolumn{4}{|c|}{ Post-intervention } & & \\
\hline & \multicolumn{2}{|c|}{ Satisfactory } & \multicolumn{2}{|c|}{ Unsatisfactory } & \multicolumn{2}{|c|}{ Satisfactory } & \multicolumn{2}{|c|}{ Unsatisfactory } & & \\
\hline & No & $\%$ & No & $\%$ & No & $\%$ & No & $\%$ & & \\
\hline Age in years & 0 & 0.0 & 120 & 100.0 & 110 & 91.7 & 10 & 8.3 & 2.40 & $>0.05$ \\
\hline Birth order & 0 & 0.0 & 120 & 100.0 & 105 & 87.5 & 15 & 12.5 & 1.91 & $>0.05$ \\
\hline $\begin{array}{l}\text { Educational } \\
\text { level }\end{array}$ & 5 & 4.2 & 115 & 95.8 & 115 & 95.8 & 5 & 4.2 & 4.28 & $<0.001 * *$ \\
\hline Residence & 8 & 6.7 & 112 & 93.3 & 108 & 90,0 & 12 & 10.0 & 0.557 & $<0.001 * *$ \\
\hline $\begin{array}{l}\text { Relation } \\
\text { with family } \\
\text { and friends }\end{array}$ & 15 & 12.5 & 105 & 87.5 & 115 & 95.8 & 5 & 4.2 & 2.87 & $<0.001 * *$ \\
\hline
\end{tabular}

$\mathrm{P}<0.001 * *$ highly statistically significant

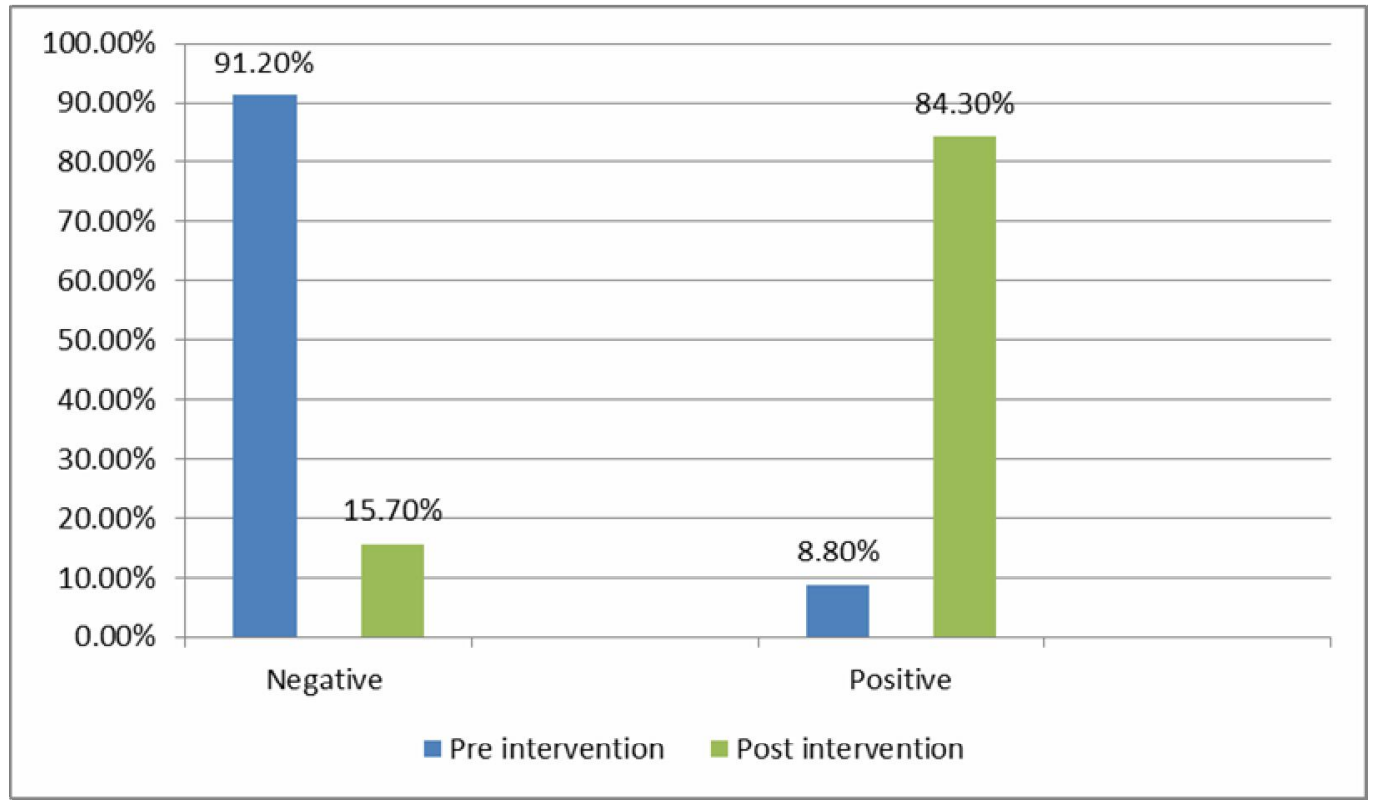

Figure (4): Percentage distribution of total attitude score of the studied students pre and post phases of intervention about masturbation. No=120 
Table (4): Relation between students` attitude score and their demographic characteristics about masturbation regarding pre and post program intervention. No=120

\begin{tabular}{|c|c|c|c|c|c|c|c|c|c|c|}
\hline \multirow{4}{*}{ Items } & \multicolumn{8}{|c|}{ Total attitude } & \multirow{4}{*}{$\begin{array}{c}\text { Chi } \\
\text { square } \\
\text { Test(1) }\end{array}$} & \multirow[t]{4}{*}{ P value } \\
\hline & \multicolumn{4}{|c|}{ Pre-intervention } & \multicolumn{4}{|c|}{ Post-intervention } & & \\
\hline & \multicolumn{2}{|c|}{ Positive } & \multicolumn{2}{|c|}{ Negative } & \multicolumn{2}{|c|}{ Positive } & \multicolumn{2}{|c|}{ Negative } & & \\
\hline & No & $\%$ & No & $\%$ & No & $\%$ & No & $\%$ & & \\
\hline Age in years & 6 & 5.0 & 114 & 95.0 & 112 & 93.3 & 8 & 6.7 & 2.40 & $<0.001 * *$ \\
\hline Birth order & 4 & 3.3 & 116 & 96.7 & 115 & 95.8 & 5 & 4.2 & 1.91 & $<0.001 * *$ \\
\hline $\begin{array}{l}\text { Educational } \\
\text { level }\end{array}$ & 5 & 4.2 & 115 & 95.8 & 115 & 95.8 & 5 & 4.2 & 4.28 & $<0.001 * *$ \\
\hline Residence & 7 & 5.8 & 114 & 94.2 & 109 & 90,8 & 11 & 9.2 & 0.557 & $<0.001 * *$ \\
\hline $\begin{array}{l}\text { Relation with } \\
\text { family and } \\
\text { friends }\end{array}$ & 10 & 8.3 & 110 & 91.7 & 115 & 95.8 & 5 & 4.2 & 2.87 & $<0.001 * *$ \\
\hline
\end{tabular}

$\mathrm{P}<0.001^{* *}$ highly statistically significant

Table (5): Correlation coefficient between total students' knowledge and attitude scores during pre/post discharge program implementation. $\mathrm{No}=120$

\begin{tabular}{|l|l|c|c|c|c||}
\hline \hline \multirow{2}{*}{$\begin{array}{l}\text { Variable } \\
\text { Knowledge }\end{array}$} & $\begin{array}{c}\text { Knowledge } \\
\text { pre }\end{array}$ & $\begin{array}{c}\text { Attitude } \\
\text { pre }\end{array}$ & $\begin{array}{c}\text { Knowledge } \\
\text { post }\end{array}$ & $\begin{array}{c}\text { Attitude } \\
\text { post }\end{array}$ \\
\hline pre & Pearson Correlation & & .008 & .226 & .138 \\
\cline { 2 - 6 } $\begin{array}{l}\text { Attitude } \\
\text { pre }\end{array}$ & Sig. (2-tailed) & & .942 & .257 & .168 \\
\cline { 2 - 6 } $\begin{array}{l}\text { Knowledge } \\
\text { post }\end{array}$ & Sig. (2-tailed) & .740 & & .119 & .005 \\
\cline { 2 - 6 } $\begin{array}{l}\text { Attitude } \\
\text { post }\end{array}$ & Pearson Correlation & .222 & .371 & .080 & .865 \\
\cline { 2 - 6 } & Sig. (2-tailed) & .367 & .090 & & .060 \\
\cline { 2 - 7 } & Pearson Correlation & .257 & .005 & -.450 & .598 \\
\hline
\end{tabular}

Table (6): Students' opinion of educational program about masturbation. (No=120)

\begin{tabular}{||l|c|c|c|c||}
\hline \multirow{3}{*}{ Items } & \multicolumn{4}{|c||}{ Post program } \\
\cline { 2 - 5 } & \multicolumn{2}{|c|}{ Unsatisfactory } & \multicolumn{2}{c||}{ Satisfactory } \\
\cline { 2 - 5 } & NO & \% & NO & \% \\
\hline Knowledge of program & 0 & 0.0 & 120 & 100.0 \\
\hline Time of program & 5 & 4.2 & 115 & 95.8 \\
\hline Language of program & 4 & 3.3 & 116 & 96.7 \\
\hline Discussion method of program & 0 & 0.0 & 120 & 100.0 \\
\hline Place of program & 10 & 8.3 & 110 & 91.7 \\
\hline \hline
\end{tabular}




\section{References}

1. Almogela L, Cacapit Z, Caldito, R, Corpuz, A, Domede K., Fajardo C, Garcia M, Lacap J, Magsingit C, Mangaoang K, Pasiliao F, Sayson J, Cacanindin C, Saint Louis University School of Nursing: The Relationship of Self- Esteem and HealthRelated Behaviors among Adolescents in Baguio City. Available at: Research Congress, De La Salle University, Manila, (March 7-2013).

2. Jump U, Aldo P. Animal Homosexuality: A Biosocial Perspective. Cambridge University Press. ISBN 978-1-139-49038-2 (2010).

3. Richardsom J, Mark A S. Everything You Never Wanted Your Kids to Know about Sex, but Were Afraid They'd Ask: The Secrets to Surviving Your Child's Sexual Development from Birth to the Teens. New York: Crown Publishers (2012).

4. Cynthia LR, Vanessa S, Michael R, Debra $\mathrm{H}$, Stephanie AS, Brian DJ, Dennis F. Prevalence, Frequency, and Associations of Masturbation with Partnered Sexual Behaviors among US Adolescents. Available at: American Medical Association. (2017) http://jamanetwork.com/pdfaccess.ashx?url= /data/journals/peds/22559/

5. Jump U, Hallikeri VR, Gouda HS, Aramani SC, Vijaykumar AG, Ajaykumar TS. "Masturbation-an Overview". Journal of Forensic Medicine and Toxicology. New Delhi: Medicolegal Society. 27(2): (2010)46-49. ISSN 0971-1929.

6. Blume LB, Zembar MJ. Child and Adolescent Development, Adolescent Sexuality- Pearson Allyn Bacon Prentice HallPMID 17315592. .,(2010)CS1.

7. Ali RAS, Abd-El Aal EM. Effect of Health Educational Program for Females Blinded Adolescents Students Regarding Reproductive Health. American Journal of Nursing Science. Vol. 4, No. 1, 2015, pp. 18. doi: 10.11648/j.ajns.20150401.11
8. Walter BO, Coleman E. Masturbation as a Means of Achieving Sexual Health. New York: Haworth Press (2011).

9. Richardsom J, Mark A S. Everything You Never Wanted Your Kids to Know about Sex, but Were Afraid They'd Ask: The Secrets to Surviving Your Child's Sexual Development from Birth to the Teens. New York: Crown Publishers (2013).

10. Fahs B, Frank E. Notes from the Back Room: Gender, Power, and (In) Visibility in Women's Experiences of Masturbation. Journal of Sex Research. doi:10.1080/00224499.2013.745474.

11. Xinli C, Lu Y, Winter S. Prevalence and Correlates of Sexual Behaviors among University Students: A study in Hefei, China BMC Public Health. Published online 2012 Nov 13. doi: $\underline{10.1186 / 1471-2458-12-972}$ PMCID: PMC3527150.

12. Christie D, Viner R. Adolescent Development. Available doi: 10.1136/bmj. 3307486.301pmc 548185. PMID 15695279; Pp 301-304(2012).

13. Yamane T. Statistics an Introductory Analysis. 2nd Ed. New York Harper and Row CO.USA, (1967), 213.

14. Fisher TD, Davis CM, Yarber WL, Davis SL. Handbook of Sexuality-Related Measures. New York: Routledge (2010).

15. Stephen K. Complications-overmasturbation-and-how-solve-them. 2017. Available at: www.herballove.com/case.../

16. Wang R, Huang Y, Lin Y. A study of Masturbatory Knowledge and Attitudes and related Factors among Taiwan Adolescents. J Nurs Res. 2017 Sep; 15(3):233-42.

17. Wilson S, Medora N. Gender Comparisons of College Students' Attitudes toward Sexual Behavior. 25(99):615-27. (2015).

18. Garde K, Lunde I. Influence of Social Status on Female Sexual Behaviour. A Random Sample Study of 40-year-old Danish Women ISSN: 0281-3432 (Print) 1502-7724 (Online) Journal homepage: (2010) http://www.tandfonline.com/loi/ipri20. 
19. Hansen J, Lloyd R. Is Attitude toward Masturbation Related to Sexual Arousal? Andrologia 47:336-342, (2015).

20. Ray J, Afflerbach sh. Sexual Education and Attitudes toward Masturbation, "Journal of Undergraduate Research at Minnesota State University, Mankato: Vol. 14, (2014) Article 8. Available at: http://cornerstone.lib.mnsu.edu/jur/vol14/iss $\underline{1 / 8}$.
21. How to prevent masturbation. Available at http://timesofindia.indiatimes.com (2017).

22. 22-Ways to Stop Masturbation: Available at http://www.MD-HEALTH.COM (2017).

23. Let's Talk About Masturbation!. Available at: http://wwwCopyright@2016. Identity Magazine. 